\title{
Free/Open Source Software Adoption, Public Policies and Development Indicators: An International Comparison
}

\author{
Harald Schmidbauer ${ }^{1}$, Mehmet Gençer ${ }^{2}$, and Vehbi Sinan Tunalıo lu ${ }^{2}$ \\ 1 Istanbul Bilgi Üniversity, Department of International Finance, \\ harald@bilgi.edu.tr \\ 2 Istanbul Bilgi Üniversity, Department of Computer Science, \\ \{mgencer,vst\}@cs.bilgi.edu.tr
}

\begin{abstract}
Despite the growing body of research on the inner workings of FOSS development, there are few studies on its relation with broader developments in society. In this study we have attempted a preliminary investigation of (1) how FOSS prevalence is related to economic and human development indicators of countries, (2) whether public policies regarding FOSS emerge in a consistent relation with these indicators in several clusters of countries constructed from the United Nation's human development index, and (3) the relation of software piracy to development indicators. Our results point to relative significance of non-economic factors in FOSS adoption, lack of consistent policies among public agencies, and irrelevance of non-economic factors on software piracy. In addition, the study demonstrates the possibility of developing FOSS indices for larger scale diagnosis and strategizing.
\end{abstract}

\section{Introduction}

The development of policies towards Free and Open Source Software (FOSS), whether public or private, requires a better understanding of how FOSS adoption interacts with various aspects of society. While the growing body of research on FOSS focuses on community, governance, and coordination of production activity $[6,4]$, or relations to wider software industry [3,11], studies on relation of FOSS with broader developments in society and factors which affect its adoption are seldom $[1,2]$.

In this study we have attempted a preliminary investigation of these relations. We first address the following empirical questions: (1) how FOSS adoption is related to economic and human development indicators of countries, and (2) whether public policies regarding FOSS emerge in a consistent relation with these indicators in several clusters of countries. In addition, (3) relation of software piracy to development indicators is considered in order to highlight deficiencies in policies involving proprietary software. Building on our results and research elsewhere, we then discuss policy choices accounting for economic reality.

Corresponding methods for our investigation are as follows:

1. For an international comparison of FOSS adoption, we particularly tried to assess the variability in the occurrence of FOSS across countries on the basis of several

Please we the following format when citing this chapter:

Schmidbauer, H., Gencer, M. and Tuanlio_lu, V.S., 2007, in IFIP International Federation for Information Processing, Volume 234, Open Source Development, Adoption and Innovation, eds. J. Feller, Fitzgerald, B., Scacchi, W., Sillitti, A., (Boston: Springer), pp. 331-336 
variables related to human development, economics and transparency, and the Internet infrastructure. Adoption of FOSS in a country is operationalized as the number of hits in the country-specific Google search of the keyword "open source". This variable will obviously be correlated with the size of a country in terms of its population.

2. To assess the relation of public policies towards using FOSS with development indicators, we have attempted to relate it to a classification of countries we have developed on the basis of cluster analysis. FOSS usage in public agencies is operationalized through the server software type used in several public bodies in countries.

3. Deficiencies in policies involving proprietary software is examined through an analysis of piracy data for countries in relation to development indicators. For this purpose piracy rate data published by BSA was checked for its correlation to human development, economics and transparency indicators.

Our results point to (1) relative significance of non-economic factors in FOSS adoption, (2) lack of consistent policies among public agencies towards FOSS, and (3) strong dominance of economic factors and irrelevance of non-economic factors on software piracy. The finding that FOSS adoption is correlated to human development index, which is defined as "a process of enlarging people's choices" [10], is supportive of the claims that public promotion of FOSS through information campaigns can indeed be effective [1]. Furthermore, we argue that given the economic conditions in relatively less developed countries, public intervention in the software market through promoting open source is not only favorable [2], but possibly inevitable if sensible conditions in software market (such as reduced piracy) are desired. On the other hand lack of consistent public policies indicates lack of awareness among policy makers towards the potential of open source software, in effect disengaging large communities from enjoying its benefits.

The following three sections lay out quantitative data, models and results for relating development indices to FOSS adoption, public policies towards FOSS and software piracy, respectively. A discussion of results in section 5 attempts to interpret these results, followed by conclusions.

\section{FOSS Adoption}

Our investigation of the FOSS adoption is based on regression models with Google counts of "open source" as dependent variable and a selection of independent variables from the following list: population, gross domestic product (GDP), human development, index (hdi), transparency index (tri), Internet usage, relative Internet usage, number of Internet hosts in the country.

In order to account for the impact of economic reality, we use GDP per capita, the transparency index and Internet usage as proxies to the adoption of FOSS. We also relate FOSS adoption to human development. We choose the human 
development index (despite ongoing debates, see, for example [5,8]), which is published by the United Nations Development Program (UNDP) [10].

A full regression model, with all variables included as regressors, and fitted to 116 cases (countries) for which the entire data set was available, has an explanatory power (i.e., $R^{2}$ ) of $67 \%$, but leaves many variables insignificant. Using stepwise procedures to fit a reduced model with fewer, and significant variables, leads to the following model, fitted to 129 cases (The numbers in parenthesis are the $t$ values of the estimates):

$$
\begin{aligned}
\log (\log (\text { count. opent. gource }))= & -1.546+ \\
(-2.13) & =0.8155 \times \log (\log (\text { population })) \\
& +0.0485 \times \log (\text { internet host }) \\
& (4.11) \\
& +\frac{1.3070 \times \text { hdi }}{(5.44)}
\end{aligned}
$$

This model also has an $R^{2}$ of about $67 \%$, while retaining only significant regressors. A comparison of the regressors in this model with the list of variables in the table above reveals that Internet usage, relative Internet usage, the transparency index, and GDP per capita are not significant in explaining the variability of Google counts of "open source" across countries.

It may come as a surprise that GDP per capita has so little explanatory power on the adoption of FOSS compared to hdi. To reassess this result, another regression model, with GDP per capita substituted for hdi, can be fitted to the data set. The explanatory power of such a model is substantially smaller than the model cited above; its $R^{2}$ is reduced to $61 \%$. We can thus conclude that economic well-being can indeed explain a certain share of variability contained in the dependent variable, but the explanatory power is further enhanced by considering non-economic factors. This highlights the importance of non-economic factors in accounting for the prevalence of FOSS.

\section{Public Policies}

Is there a pattern in the server software variety used by governmental organizations across countries? To provide an answer to this question, we have looked into the server software choice (open source vs proprietary) in several prominent public bodies of countries; these are the bureau of statistics, the central bank, the finance regulator, the foreign ministry, and the postal services. In addition we have clustered countries with respect to the variables discussed earlier. Finally, we have tested the null hypothesis that cluster membership and the server software variety are independent.

A cluster number of 5 was found optimal to account for differences between the countries. The five clusters (based on a $k$-means cluster analysis with standardized variables) can be summarized as follows: 
- Cluster 1: Low relative Internet usage, mid-range hdi; mid-range open-source count reflecting the mid-range population of the country.

- Cluster 2: Low relative Internet usage, mid-range hdi; low open-source count reflecting the smaller size of the country as compared to Cluster 1.

- Cluster 3: Low relative Internet usage, mid-range hdi; higher open-source count reflecting the larger size of the country as compared to Cluster 1.

- Cluster 4: Highest relative Internet usage, highest hdi; very high open-source count, almost irrespective of the population size.

- Cluster 5: Very low relative Internet usage, very low hdi.

Figure 1 shows a classification tree. It illustrates how the cluster membership of a country is determined: if the condition on a fork is fulfilled, the left branch applies, and vice versa.

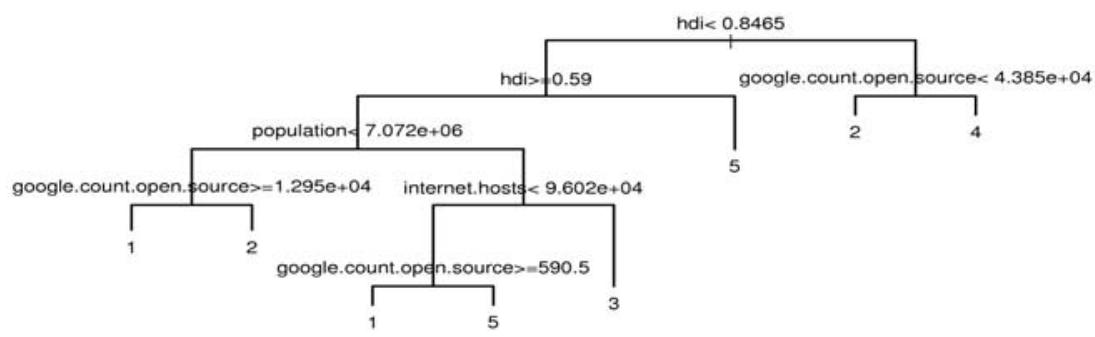

Fig. 1: Classification tree for clusters of countries

Table 1 shows the server software counts for public bodies in different clusters, with countries for which no data were available omitted. Since the main difference between Clusters 1, 2 and 3 is population size, it is justified to collapse them into a single cluster and increase the power of the ${ }_{-}^{2}$ test. The p-value of the null hypothesis that "server software choice and cluster membership is independent", as shown in the last row of the mentioned table, shows that it is rejected only in the case of the bureau of statistics.

Table 1: Cluster membership and server software variety $(f=$ free, $p=$ proprietary)

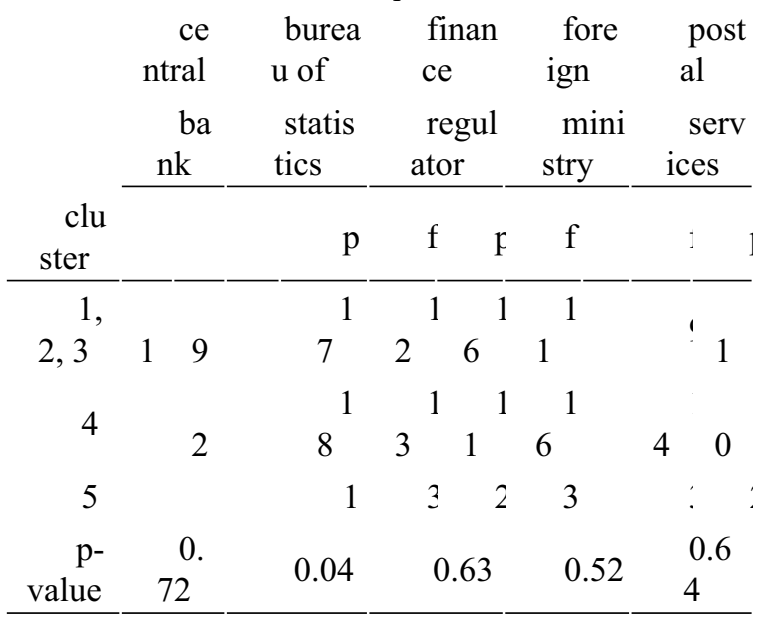


A related question is: Is there evidence that the variety of server software used in one organization of a country is associated with that used in another one? We found no case in which the hypothesis of independence of server software variety in different organizations could be rejected. In this sense, we found no evidence of a consistent server software policy pattern within countries.

\section{Software Piracy}

In what way is software piracy connected with the variables listed above, and with FOSS prevalence in particular? Insight into these matters may have consequences concerning policies to reduce software piracy supported by a policy to promote FOSS. The most comprehensive data for software piracy across countries comes from Business Software Alliance (BSA), despite debates regarding its reliability. Fitting a regression model with privacy as dependent variable and independent variables logged GDP per capita and transparency index to the 66 available cases leads to

$$
\text { piracy }=\underset{(8.03)}{201.37}-\frac{13.263 \times \log (\mathrm{gdp} \cdot \mathrm{pc})}{(-4.39)}-\frac{3.6566 \times \mathrm{tri}}{(-4.04)}
$$

This model has an $R^{2}$ of 0.787 . The fact that the human development index shows no significance reveals dominance of economic factors on software piracy.

Another far-reaching aspect with regard to policy finding may be the correlation between piracy and FOSS adoption (operationalized as Google counts of "open source") across countries. This correlation is a moderately distinct 0.44 . This correlation may be spurious, however, since both variables are closely linked to GDP. Indeed, the partial correlation between piracy and FOSS adoption, controlling for GDP per capita, turns out to be close to 0. A preliminary conclusion is that promoting FOSS adoption, without accompanying measures, need not be a cure against software piracy.

\section{Discussion}

As explained in the previous section, we found no evidence that governments pursue a server policy. Based on macro-economic models, Comino and Manenti have recently pointed out that regarding open source software "there may be a substantial mass of uniformed consumers, leading to market failures that may justify government intervention" [1]. Results of our empirical comparison also directs in similar ways that non-economic factors are an important determinant in harvesting of potential advantages FOSS provides. But more importantly it highlights that development of "free and open source indices" of better precision can be very empowering for all parties in the game as they as their interpretation can help in policy making. 


\section{Conclusions}

In an effort to assess the determinants of the prevalence of Free and Open Source Software (FOSS), we have tried to account for the variability in Google counts of the keyword "open source" across countries worldwide using a regression model with several regressors characterizing human development, the economic situation, and Internet infrastructure of the countries considered. It turned out that the human development index, population, and the number of Internet hosts are significant, while Internet usage is not. A cluster analysis of the country data pointed at the interplay of human development and FOSS prevalence in public agencies. We found that the bureau of statistics is the only example among several prominent public organizations of a country whose server software variety (free or proprietary) is significantly related to the cluster membership of countries.

We conclude from our models that GDP per capita is less important in accounting for prevalence of FOSS. It is rather information campaigns and educational incentives that may be conducive to widespread use of FOSS.We mentioned earlier that FOSS introduced its own mode of production, in which human capital plays the most important role. The study by Streeten [12] emphasizes that "human beings are both ends in themselves and means of production". With respect to that, we suggest that FOSS be further discussed under the aspect of its contribution to human development.

\section{References}

1 Comino S, Manenti FM (2005) Government Policies Supporting Open Source Software for the Mass Market. Review of Industrial Organization 26(2):217-240.

2 Dalle JM, Jullien N (2003) Libre software: turning fads into institutions? Research Policy 32(1):1-11.

3 Garud R, Kumaraswamy A. (1993) Changing competitive dynamics in network industries: an exploration of Sun Microsystems' open systems strategy. Strategic Management Journal 14(5):351-369.

4 Hippel Ev, Krogh Gv (2003) Open source software and the private-collective innovation model: Issues for organization science. Organization Science 14(2):209-223.

5 Kelley AC (1991) The Human Development Index: "Handle with Care". Population and Development Review 17(2):315-324.

6 Kogut B, Metiu A (2001) Open source software development and distributed innovation. Oxford Review of Economic Policy 17(2):248-264.

7 Srinivasan TN (1994) Human Development: A New Paradigm or Reinvention of the Wheel? The American Economic Review 84(2):238-243.

8 Streeten P (1994) Human Development: Means and Ends. The American Economic Review 84(2):232-237.

9 Transparency International (2004) Annual Report 2004 - The Coalition Against Corruption. Transparency International

10 UNDP (1990) Human Development Report 1990. Oxford University Press, New York, Oxford.

11 West J (2003) How open is open enough: melding proprietary and open source platform strategies. Research Policy 32(7):1259-1285. 